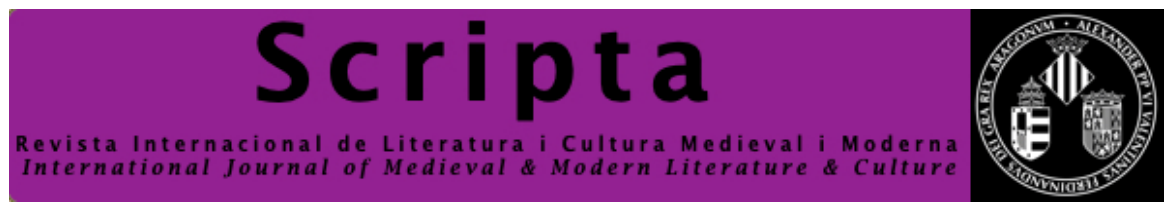

\title{
De l'[EMOció] a la [CONTRA voluntat]: el procés de gramaticalització de malgrat als segles XII-XVI
}

\author{
From [emotion] to [AgAinst WILL]: the Process \\ of Grammaticalization of malgrat in the 12th-16th centuries \\ Caterina Martínez \\ caterinamm91@gmail.com
}

Universitat d'Alacant

\begin{abstract}
Resum: L'estudi que presentem se centra en el procés de gramaticalització de malgrat, des del paper com a Sintagma Nominal originari que expressa una [EMOCIÓ] fins al valor de [CONTRA VOLUNTAT] que arribà a assolir com a Sintagma Preposicional. Parem esment especialment en la retracció que experimentà malgrat justament a partir del segle xvi. Examinem l'evolució de malgrat segons les propostes de la Lingüística Cognitiva i, concretament, la Teoria de la Gramaticalització, i les combinem amb els plantejaments de l'Anàlisi del Discurs, la Teoria de l'Argumentació i la Pragmàtica. La defensa del canvi lingüístic arrelat en l'ús, d'acord amb la Teoria de la Intersubjectivació, ens ajuda a revisar les fonts i els valors de malgrat en català.
\end{abstract}

Paraules clau: malgrat, gramaticalització, intersubjectivació, connector parentètic, desgrat, contra voluntat, concessivitat, focalització, retracció.

Abstract: The present study focuses on the process of grammaticalization of malgrat, from the paper as an original Noun Phrase expressing an [EMOTION] to the value of [AGAINST WILL] that it has reached as a Preposition Phrase. We pay special attention to the retraction experienced by malgrat just as from the 16th century. We examine the evolution of malgrat according with the proposals of Cognitive Linguistics and, specially, the Theory of Grammaticalization, and we combine them with the approaches of Discourse Analysis, Argumentation Theory and Pragmatics. The defense of the linguistic change rooted in the use, in accordance with the Theory of Intersubjectivity, helps us to review the sources and the values of malgrat in Catalan.

Keywords: malgrat, grammaticalization, intersubjectification, parenthetical connector, displeasure, against will, concessivity, focusing, retraction.

\footnotetext{
$-$

* Aquest estudi s'ha dut a terme a l'Institut Superior d'Investigació Cooperativa IVITRA [ISIC-IVITRA] de la Generalitat Valenciana (Programa per a la Constitució i Acreditació d'Instituts Superiors d'Investigació Cooperativa d'Excelllència, Ref. ISIC/012/042), i en el marc dels projectes de recerca següents: «Gramàtica del Català Modern (1601-1834)» (MINECO, Ref. FFI2012-37103); «Continuación de la Gramática del Catalán Moderno (1601-1834)» (MINECO/FEDER, Ref. FFI2015-69694-P); «Constitució d’un corpus textual per a una gramàtica del català modern (Gcm)» (IEC, Ref. PT 2012-S04-MARTINES; IEC1-15X); Digicotracam (Programa PROMETEU per a Grups d'Investigació en I+D d'Excellència, Generalitat Valenciana, Ref. PROMETEOII-2014-018), finançat amb fons FEDER de la UE; i el Grup d'Investigació en Tecnologia Educativa en Història de la Cultura, Diacronia lingüística i Traducció (Universitat d'Alacant, Ref. GITE-09009-UA]).
} 


\section{Caterina Martínez. De l'[emoció] a la [CONTRA voluntat]: el procés de gramaticalització de}

malgrat als segles XII-XVI

\section{Introducció}

\subsection{Presentació}

Atesa la concepció del text-discurs defensada per la lingüística de caire cognitivista, l'interès per aquestes peces lingüístiques ha crescut, a un ritme exponencial, entre les darreres i les primeres dècades dels segles XIx i xx (Garachana, 2014). Especialment, la Teoria de la Gramaticalització i l'Anàlisi del Discurs, juntament amb la Pragmàtica, la Teoria de la Inferència Invitada del Canvi Semàntic i les darreres aportacions centrades en la importància de l'interlocutor -la Subjectivació i la Intersubjectivació (Nuyts, 2005; Traugott, 2010; Narrog, 2012)- ens permeten distingir amb més claredat les diverses funcions dels connector dins el discurs; fonamentalment: la funció additiva, disjuntiva, contrastiva o consecutiva.

Els canvis lingüístics que menen al llarg del temps fins a la generació d'un connector posen en escena la dinàmica de les inferències del parlant/escriptor (Pt/Er), l'oient/lector (Ot/Lr) i el text/ discurs (T/D). Els aspectes més estudiats dels «connectors parentètics» (Cuenca, 2001; 2006) han estat, precisament, l'evolució diacrònica i les fonts que els han generat. Fins ara, en català, han estat estudiats, diacrònicament i des d'aquest punt de vista: la disjunció reformulativa de ço és (a saber) (Garachana, 2013), provinent de la noció d'[EQUIVALĖNCIA]; el contrast adverdsativoconcessiu de noresmenys (i nogensmenys) i tanmateix (Martínez, 2018), vinculats amb el [CÀLCUL]; i l'origen [TEMPORAL] i d'[experiència emocional] dels contrastius concessius encara que (Pérez Saldanya \& Salvador, 1995) i baldament (Martínez, en premsa), respectivament. En aquesta línia, ens disposem a analitzar el primerenc procés de gramaticalització de malgrat, un altre connector que, generat en l'[EXPERIÈNCIA EMOCIONAL], ha aconseguit d'expressar el contrast concessiu.

\subsection{Estat de la qüestió}

Des dels segles XIX-Xx ençà, trobem al lusions a malgrat, com a Sintagma Nominal i com a Sintagma Preposicional, en diccionaris com ara, el DLabèrnia (1865, s. v. malgrat), que qualifica malgrat d'adverbi amb el significat de 'a la força, de mala gana'; el DMistral (1878, s. v. mau-grat, mal-grat) que especificava que, com a variant romànica catalana de la preposició, malgrat era equivalent a 'malgré, nonobstant', 'mauvais gré' i constituïa una «imprecació»; el D’Escrig (1891, s. v. grat), que recollia «de bò o mal grat», 'con mucho gusto, o de mala voluntat o contra la voluntat de uno'; i el DAguiló (1924, s. v. malgrat), que feia malgrat equivalent de «a pesar».

El $D C V B$ (s. v. malgrat) recull, en la primera entrada, el significat de 'sentiment desagradable, d'aversió' del substantiu antic -vg. (2)-. I, en la segona entrada, com a preposició seguida d'una estructura de genitiu o d'un possessiu, volia dir 'sense que ho impedeixi l'oposició (de tal o tal cosa)' -vg. (8), (11) i (24)-. I el DECat (s. v. grat) compila exemples de «la construcció adverbial absoluta mal grats. Documenta la construcció prepositiva, mal grat de, al segle XII -(4)-i constata que, tot i ser 
Caterina Martínez. De l'[EMOció] a la [CONTRA voluntat]: el procés de gramaticalització de malgrat als segles XII-XVI

equivalent a malgrat + possessiu -(12)-, la variant amb preposició havia acabat per imposar-se -(6), (8) i (10)-.

Entre els lingüistes i els gramàtics contemporanis, Badia (1994: 326) qualificava malgrat com a propi d'un nivell de llengua elevat. Al seu torn, Cuenca (1990; 2001; 2006) explica malgrat com un complex sintagmàtic, resultant d'una gramaticalització d'elements no conjuntius, és a dir, com un «connector parentètic».

Actualment, la Gramàtica del Català Contemporani (GCC, 2002: 3017) verifica que és molt viu en diversos registres, sobretot, formals. I, la Gramàtica de l'Institut d'Estudis Catalans (GIEC, 2017: 720) explica que malgrat de (i a malgrat de o malgrat + possessiu), propi de la llengua antiga, s'ha convertit en una marca estilística d'autor. Atesos l'antiguitat (TLFi, s. v. malgré documentat des de 1225) i l'arrelament en l'ús que té el paral lel malgré en francès i el nul ús popular de malgrat en català, aquest sovint havia estat considerat com a gal licisme o com a arcaisme. Malgrat és antic en català i respon, com veurem, a un procés de gramaticalització que deu ser semblant al seguit per malgré i altres connectors romànics d'aquesta mena. I, de l'altra banda, com també tindrem oportunitat de mostrar ací, malgrat va tenir un notable arrelament en català fins a un determinat moment de la història de la llengua en què va decaure dràsticament $i$ ha experimentat un reviscolament en registres formals.

Certament, fins a hores d'ara, aquest procés de gramaticalització de malgrat i d'altres mots connexos provinents de compostos amb grat no ha estat analitzat en profunditat, en cap de les llengües romàniques, des d'una perspectiva pragmàticodiscursiva, com la que ací pretenem dur a terme.

\section{Metodologia i hipòtesi de treball}

El canvi semàntic que experimenta malgrat mostra l'evolució prototípica d'una mena de peces lingüístiques, altament lligades a l'interlocutor, i, per tant, altament modalitzades i sotmeses a un procés d'Intersubjectivació (Traugott, 2010; Nuyts, 2005; Narrog, 2012): els connectors parentètics. Seguint els estudis de Cuenca (2001; 2006: 54-61), definim la categoria de «connector parentètic» com un element invariable que funciona de manera connectiva i que, pel fet de passar o d'haver passat per un procés de gramaticalització, es caracteritza sintàcticament per ser apositiu, combinable i mòbil.

Els connectors parentètics com malgrat, en un bon grapat de llengües, provenen d'elements que es corresponen, morfològicament, amb Sintagmes Preposicionals o amb unitats sintagmàtiques més complexes que, al seu torn, van brollar d'una font lèxica tan primària com l'[EXPERIĖNCIA EMOCIONAL] -positiva, com ara, maguer(a) (que) (Montero, 1992; Ibba, 2008; Pérez Saldanya, 2014), baldament (que) (Martínez, en premsa) o bé que; o bé, negativa, a pesar (de) (Pérez Saldanya, 2014), a desgrat (de), a despit (de) o mal que - i que han desembocat en l'expressió gramatical del contrast 
Caterina Martínez. De l'[EMOció] a la [CONTRA voluntat]: el procés de gramaticalització de malgrat als segles XII-XVI

concessiu. De fet, d'acord amb la classificació de les fonts de la [CONCESSIVITAT] de König (1985: 268), situem malgrat entre els membres del quart grup, aquells que lexicalitzen directament les nocions 'pejoratives' (Harris, 1988: 84), 'de disconformitat' o 'de refús' (Salvador, 2010: 23 i 29), 'de desaprovació' (Pérez Saldanya, 2014: 3713), 'psicològiques' (Rofes, 2017), 'una emoció negativa relacionada amb el dolor, la pena o el disgust' (GIEC, 2017: 1159) de [CONFLicte], [OBSTINACió], [DISSONÀNCIA] o [EXPERIĖNCIA EMOCIONAL], és a dir, les nostres reaccions davant de certes situacions (Martínez, 2018: 144; en premsa). D'aquesta manera, en les llengües romàniques hi havia o hi ha les formes equivalents: mal grat de, mal grat + possessiu i mal + possessiu + grat (en occità); malgré (o mangrê i malgré a (en francès); (a) mal + possessiu + grado, (a) + possessiu + malgrado, (a) malgrado di, (a) malgrado a i malgrado (en italià) (Consales, 2005); a mal de + possessiu + grado, mal de + (possessiu) + grado, a (todo) + possessiu + mal grado i mal grado $+a($ en espanyol); i, (a) mao + possessiu + grado $\mathrm{i}$ a mao grado (en portuguès).

Aquest estudi es fonamenta en els materials extrets del CICA i el CIMTAC (CIGCa i CIGMod). Hem aprofitat també exemples presos de despullaments propis, manuals i digitals. Amb tot plegat hem confegit un inventari d'exemples que considerem representatiu de l'evolució de malgrat des del segle XII fins al segle XVI, des de la noció de [DESGRAt] fins a la [CONTRA VOLUNTAT].

Com veurem tot seguit, des de mitjan segle XII, hem trobat documentació catalana que palesa com de primerenc i de truncat fou el procés de gramaticalització de malgrat.

A manera de guia, vet ací l’itinerari de gramaticalització de malgrat:

Fase I. Malgrat Sintagma Nominal: [+animat]

a) valor de [DESPLAER] experimentat i/o observat i expressat ('mal sentiment') $[((-(\operatorname{EdC})) \otimes)]^{1}>$

Fase II. Malgrat Sintagma Preposicional: [+animat]

a) valor de [CONTRA VOLUNTAT] experimentada i/o observada i expressada ('contra la voluntat d'algú') $[-(-(-(E d C \vee))(\$)]>$

\footnotetext{
1 La formulació [-(EdC)] simbolitza l'experimentació de desplaer provocat per 'un Estat de Coses'. Aquest desplaer d'EdC és, en principi, experimentat pel Pt/Er. Posteriorment, aquesta experimentació de desgrat per un EdC concret del Pt/Er pot ser observada pel mateix Pt/Er o per l'O/E: [(-(EdCY))]. I, seguidament, l’observació per part del $\mathrm{Pt} /$ Er o de l'Ot/Lr de l'experimentació de l'aversió per un EdC, aliena o pròpia, és expressada [((-(EdC)) (ه) ]. Així, aquest EdC, provoca com a reacció un sentiment desagradable, no volgut, i, per tant, contra voluntat humana $[-(-(\operatorname{EdC})) \otimes)$
}

SCRIPTA, Revista internacional de literatura i cultura medieval i moderna, núm. 12/ desembre 2018/pp. 86-102 ISSN: 2340 - 4841 doi:10.7203/SCRIPTA.12.13665 
Caterina Martínez. De l'[EMOció] a la [CONTRA voluntat]: el procés de gramaticalització de malgrat als segles XII-XVI

\section{Anàlisi dels resultats}

\section{Fase I. Malgrat Sintagma Nominal: [DESPLAER] [+animat]}

Com és sabut, la gramaticalització (Traugott, 1990) és un tipus de canvi lingüístic en el qual una unitat lèxica esdevé una unitat cada vegada més gramatical arran d'un procés de reanàlisi i de canvi semàntic, en què les dinàmiques dels usuaris, és a dir, dels interlocutors, Pt/Er i Ot/Lr, fan un paper clau, a l'hora d'interpretar la informació explícita i d'inferir-ne la implícita. Així, doncs, tot i que no hem trobat exemples en dates anteriors, si recorrem al mot originari grat, 'satisfacció', 'gust' (DCVB, s. v. grat), és de suposar que, de bell començament, malgrat va començar essent una unitat lèxica provinent de male GRATum en llatí, és a dir, un Sintagma Nominal, compost per un adjectiu i un nom -vg. (1), (2) i (3) - al segle xv:

(1) E què fa lo senyor? Apresone'ns; tramet a tu una malaltia per purgar tos peccats, per tal que ls pachs. E tu, què fas llavors? Quan los dolors te vénen, rebats lo colp renegant mal grat etc.

(Sant Vicent Ferrer, 1410, segle xva, Sermons, p. 252)

(2) Puys, per les flos / de què 's nodrien / dins, e 's pexien / per los melichs, / pobres e richs, / han per egual / tots, semblant mal: / piguotes, rosa. / Mas, si ls fa nosa / lo fill qu'és nat / he n’àn mal grat, / no ls plau que vixcha. /D'ells fan perixcha / bollit, cremat, / nu soterrat.

(Jaume Roig, 1460, segle xvb, Spill, 1. 9019; DCVB, s. v. grat)

(3) Donchs, per què 1 vell, podrit, ruat, / no pot penssar / que del mal grat discobre clar /lo testimoni? /Donchs, què direm del matrimoni? /Aquí sta 1 punt! (Jaume Gassull, 1497, segle xvb, Lo Somni de Johan Johan, 1. 1749)

En canvi, com veurem, malgrat ja va aparèixer, a la segona meitat del segle xII, com una unitat gramatical, una partícula introductora d'un Sintagma Preposicional Complement Circumstancial de Mode (gramaticalitració primària de Traugott, 1990).

\section{Fase II. Malgrat Sintagma Preposicional: [Contra voluntat] [+animat]}

Efectivament, l'estructura conformada per mal grat, amb valor de [CONTRA VOLUNTAT] de 'sentiment desagradable, d'aversió' ( $D C V B$, s. v. grat), va nàixer, a la segona meitat del segle XII, com a un Sintagma Preposicional Complement Circumstancial de Mode - de vegades, apositiu o parentètic-. Aquesta funció gramatical de Sintagma Preposicional de Mode de malgrat pot respondre a dues raons: d'una banda, etimològicament, hi ha el bescanvi del pronom personal de l'ablatiu absolut llatí «MALO GRATO + pronom personal» per un possessiu (Rudolph, 1996; Rofes, 2012: 776); i, d'una altra banda, la semàntica cognitiva ens remet a la noció d'[EXPERIMENTACió EMOCIONAL]. Aquesta 'manera d'experimentar -un Subjecte Pacient- un [DESPLAER], per alguna cosa o per algú -un 
Caterina Martínez. De l'[EMOció] a la [CONTRA voluntat]: el procés de gramaticalització de malgrat als segles XII-XVI

Subjecte Agent-' és expressada, en termes de metonímia (Lakoff, 1987) com una corporeïtzació -embodiment-i, per tant, posseïda de manera abstracta (és a dir, 'experimentada') (Heine, 1997: 88). Entenem que «the possessee is a concept that is not visible or tangible, like a disease, a feeling, or some other psychological State» i podem vincular conceptualment l'[EXPERIMENTACIÓ] i la [POSSESSIÓ] del [DESPLAER] per part d'un Subjecte Pacient amb el tret [+animat] (Herrero, 2012).

Així, doncs, la [POSSESSió] del [DESPLAer] i el canvi del paper dels interlocutors-experimentadors, segons la Teoria de la Intersubjectivació (Traugott, 1989; Nuyts, 2005; Narrog, 2012), són els desencadenants de la gramaticalització de malgrat. la reanàlisi del malgrat Sintagma Nominal com a malgrat Sintagma Preposicional i el canvi semàntic del [DESPLAer] a la [CONTRA voluntat] (gramaticalitració secundària de Traugott, 1990; Pérez Saldanya, 2014: 3792).

Al llarg de tot el procés de gramaticalització de malgrat, veurem com, en primera instància, hi jau una estructura de caràcter monològic (Rossari, 2014: 240), modalitzada o subjectivada (Traugott, 1989: 34; 1995: 31; 2010: 35; Traugot \& Dasher, 2002): «the tendency of menings to become increasingly based in the speaker's subjetive belief state/atittude toward the proposition». És a dir, malgrat condensa allò que s'experimenta i, posteriorment, s'expressa pel mateix Pt/Er que es fonamenta en vincles individuals i propis com ara opinions, creences o tesis: [(-(EdC $))$. Per tant, en principi, podríem pensar que aquest sentiment de [CONTRA VOLUNTAT], subjectivat, tan sols és responsabilitat d'un interlocutor, el Pt/Er.

En segona instància, l'esquema de caràcter dialògic (Rossari, 2014: 240) o intersubjectivat de malgrat mostra que aquest sentiment de 'desgrat' pot ser, també, d'acord amb els plantejaments de Nuyts (2005: 14) i Narrog (2012), compartit, experimentat i/o observat, i, posteriorment, expressat per un altre interlocutor (o més): bé el mateix Pt/Er-speaker-orientation-, o bé l'Ot/Lr - hearer-orientation- de la situació comunicativa discursiva -textual/ discourse-orientation-, ja que tenen vincles pragmativocognitius -coneixements compartits en forma d'arguments, contraarguments, conclusions i reformulacions- i il locucionals comuns com, per exemple, l'acte de preguntaresposta: $[((-(\mathrm{EdC}))(\otimes)]$.

A partir de la segona meitat del segle $\mathrm{XII}^{2}$, trobem mali grat regits per, principalment, dues estructures:

2 En català, també al segle XIII, trobem la construcció prepositiva sense + possessiu + grat amb el verb de possessió tenir (i):

i. Clama ss R. Maasen e Na Rumia, filla que fo de Na Ferrera Maasen, als seinnors de la casa d' Orgainnà d'onor que Ferrer d'Escales ten; clama ss de nn Ferrer can la ss contradiu ne la s ten sen lur grat. Lo ja dit R. demana per raon de son avi En P. Mosen, qui teniat avia e possedia per s[e]ua aqueilla honor; tés a saber la onor a la serra subirana de Fígols. (segle ximb, Disputació entre R. Mosen i Ferrer d'Escales, p. 105, 1. 8)

I, posteriorment, al segle xv, com ja s'hi intueix, trobem també aquesta relació semàntica de [POSSESSIÓ] de 


\section{Caterina Martínez. De l'[emoció] a la [CONTRA voluntat]: el procés de gramaticalització de malgrat als segles XII-XVI}

el Sintagma Preposicional Complement del Nom amb de i l'estructura amb el pronom possessiu. Com bé argumenta Herrero (2012: 121), totes dues remeten anafòricament al tipus de reacció, és a dir, la [CONTRA VOLUNTAT] experimentada per un ésser [+animat], susceptible de tenir 'voluntat' per a experimentar el 'mal grat', el 'desgrat', un interlocutor, com dèiem adés, el Subjecte Pacient, explícit en el discurs: [-(EdC $)]$.

Així, doncs, en aquesta primera fase, en funció del Subjecte Pacient [+animat] que es focalitze o es faça referència, trobem un pronom possessiu personal -bé davant bé darrere bé al bell migque, alhora, actua de pronom personal anafòric -vg. (5) «Sen Gregori», (7) «Déu», (9) «lo rey» i (12) «lo senyor d'Agramunt»-; un Sintagma Preposicional Complement del Nom amb de -vg. (4) amb un llenguatge fortament occitanitzat «aicels qe $\mathrm{m}$ volont mal cubert», (8) «cristians e juheus» ${ }^{3}$, (10) «la regina e tot son consell», (11) «tots sos amichs et sos vassalls», (14) «els personers» i (15) «mercaders»-; o per ambdues opcions combinades -vg. (6) «el creedor del deutor» i (13) «la voluntat de Johan Johan».

l'[EXPERIMENTACiÓ] amb el verb haver, en què el malgrat és patit pels Subjectes Pacients -«lo rey» (ii) i la persona loquens, en aquests casos Jaume Roig (iii) i Ausiàs Marc (iv)- a causa dels Subjectes Agents -«el camarlenc», «les mesquines fictes beguines», «el fill» $\mathrm{i}$ «la compassió (de la mort)»-.

ii. E en aquesta manera lo rey dormí ab la reyna. E en continent que hac dormit ab ella, se donà a conèixer al dit rey que era prenys de hun fill, de què lo rey n'ach mal grat del camarlench de ço que fet havia, mas aprés li perdonà. E com lo rey hac dormit ab la reyna e fos prenyada, per exalçar sa fama anà a vesitar los santuaris de Roma, en lo qual viatge lo rey anà bé acompanyat de barons e de cavallers de Catalunya e de Lenguadoch, car menà ab ell lo egregi baró, comte de Foix, lo qual près per companyó d' armes e donant -li lo rey ses armes.

(Pere Tomic, 1438, segle xva, Històries e conquestes d'Aragó e Catalunya, p. 229, 1. 6)

iii. Per incident, / me vull llunyar, / fforaviar / hun poch del rench. / Saltar entench / ffora l cavat; / ¡tant he mal grat / de les mesquines / ffictes beguines!

(Jaume Roig, 1460, segle xvb, Spill, 1. 14501)

iv. Per molt amar ma vida és en dupte,

mas no cregau que de la mort me tema;

a poch a poch ma sperança 's fa sema

e $\mathrm{m}$ vol fugir, mas no $\mathrm{u}$ fa en corrupte.

Haja mal grat de ssa compassió,

puys no $\mathrm{m}$ serveix a mon afany guarir;

lo detardar no veda lo venir,

e creix desig, e dobla m passió.

(Ausiàs Marc, segle xvb, Poema LV, Cant d'Amor, Poesies, 1. 5)

3 De fet, Badia (2004: 267), a «L'estudi de la llengua de Ramon Llull», en relació a aquest mateix exemple, apuntava que malgrat prenia aquesta mateixa drecera semàntica cap a la [CONCESSIVITAT].

SCRIPTA, Revista internacional de literatura i cultura medieval i moderna, núm. 12/ desembre 2018/pp. 86-102 ISSN: 2340 - 4841 doi:10.7203/SCRIPTA.12.13665 
(4) E si no fos la bella cui desir,

que chascun jorn conquier pretz e gazaigna

e ls bels semblans qe $\mathrm{m}$ fai -qand la remir-

vejaire m'es ja mais jois no m sofraigna-,

cinc anz aura a la calenda maia

que m'agra 1 reis que ten Bordels e Blaia,

malgrat d aicels qe $\mathrm{m}$ volont mal cubert,

dels tres seignors e d'En Dalmaz de Biert

(Guillem de Berguedà, 1158, segle xirb, «Consirós cant e planc e plor», III; DECat, s. v. grat)

(5) Enayxí co ls ciutadans de Roma lo querien molt diligenment, éls veseren una colomna de luyn molt resplandent que devalava sobre él en aquel loc on él estava, en la cal columna vesec un ermità resclús àngels puyans e devalans del cel. Enaprés Sen Gregori fo pres per tot lo pòbol, e feren-lo consecrar, mal son grat, en sobirà bisbe. E que, mal son grat, fos él elegut en apostoli, manifestament ó pot hom veser qui lig les sues paraules.

(Anònim, 1260, segle xiIIb, Vides de Sants Rosselloneses, p. 297, 1. 8)

(6) Si alcun enpeynora a altre alcuna cosa, e és enprés entr'éls que, si lo deutor no paga a son creedor lo dit deute per què les peynores a meses, al dia entr'éls enprés e assignat, que la peynora sia encorreguda, e que jamés no la pusca reebre. Si deutor aprés del termen paga son creedor, o li consigna e comana en loc segur la paga, si él no la vol pendre, la covinença ne l'enpreniment entr'éls enprés no val, ne pot ne deu valer; e no contrastant la dita covinença, dit deutor pot e deu cobrar la sua cosa, mal grat de son creedor. Sens contrast e enbarch d'alcuna persona.

(Anònim, 1272-1279, segle xiIrb, Costums de Tortosa, p. 384, 1. 16; DECat, s. v. grat)

(7) [9] Amable fill, qual te val més, o Ia vegada o murir tots temps en foch perdurable? Ne qual te val més, murir a mort dezirable per honrar Deu, o murir a mort ahirable, la qual auciu home mal son grat, e sens que no n'à grat ne mèrit de Déu?

(Ramon Llull, 1274-1276, segle ximb, Doctrina Pueril, p. 294, 1.7 i 8)

(8) Aquella ciutat fo, en lo començament del mon, cap dels prophetes, e en aquella ciutat fo Jhesuchrist crucificat e mort, segons que is cristians crehen; e aquella ciutat han e tenen e possehexen los sarrahins, malgrat dels crestians e dels juheus; e en aquella ciutat es ligit l'Alcora, e nuyl libre ne nuyla lig no hi es tan honrada con l'Alcora.

(Ramon Llull, 1274-1276, segle ximb, Llibre de Gentil e dels tres savis, p. 244; DCVB \& DECat, s. v. grat)

(9) Yo us coman la ciutat de Albarazi que lam salvets e lam guardets, axi com pertany a bons vasalls e lleals que vosaltres sots; e yo exire de aci abhuna partida de mos cavallers; e entrar men e en Navarra, e amenare tal socos de cavallers e de géns, que yc faré levar lo rey, mal son grat. E leix-vos assí mon nabot per governador, e vosaltres fets per ell axi com fariets per mi.

(Anònim, 1283-1288, segle xirib, Crònica de Bernat Desclot, p. 4, 1. 24)

(10) En lo començament que lo Lehó hac tremeses sos missatgers e ses joyes al rey dels hòmens, $\mathrm{Na}$ Renart, qui era porter del rey, dix al rey que lo Leupart havia la pus bella bèstia a muller que fos en tot lo món. Tant loà Na Leuparda al rey $\mathrm{Na}$ Renart, que el rey se anemora de la Leuparda, e pres aquella per muller, mal grat de la regina e de tot son concell, lo qual concell hac gran pahor de $\mathrm{Na}$ 
Caterina Martínez. De l'[EMOció] a la [CONTRA voluntat]: el procés de gramaticalització de malgrat als segles XII-XVI

Renart, con veeren que hac empetrat ab lo rey tan gran cosa com fo lo felliment que el rey havia fet contre sa bona muller, e contre lo Leupart, qui era son leyal servidor: —Bell amich — dix lo Bou a $\mathrm{Na}$ anart—, gran temor hé que lo Leupart no us aucia, con sabrà que vós havets empetrat com lo rey hage forçada sa muller-.

(Ramon Llull, 1287-1289, segle ximb, Llibre de Meravelles, p. II, 135, 1. 39; DECat, s. v. grat)

(11) Ara tornaré a parlar del cèsar, qui s'aparellà ab ccc hòmens a cavall et ab m hòmens de peu per anar a Andrinípoli a veer xor Miquelli, fill major de l'emperador malgrat de tots sos amichs et sos vassalls. (Ramon Muntaner, 1325-1328, segle xivb, Crònica de Muntaner, fol 116ra, 1. 10; DCVB, s. v. grat)

(12) Com tingué la cama damunt los arçons de la cella, vench lo senyor d'Agramunt e encontrà'l enmig de la cuxa e passà-la-y de l'altra part. Ell sentí molt gran dolor de la ferida e caygué en terra mal son grat. Com Tirant lo véu axí estés en terra, cuytà devers ell però no y pogué aconseguir, tanta era la pressa de la gent.

(Joanot Martorell, 1490, segle xvb, Tirant lo Blanch, p. 4, 1. 24; DECat, s. v. grat)

(13) Ý axí fon fet, / car prestament se fon retret / a una part, / a hon molt bé hí de bon art / ell confessà / hí per escrits ell deposà / ab veritat, / sobre l que fou interrogat / lo que y sabé: / molt largament ell ho digué, / mal de son grat, / puix que lo joch era forçat.

(Jaume Gassull, 1497, segle xvb, Lo Somni de Johan Johan, 1. 1285)

(14) E si el per ventura hi haurà perdut, personer algu no li es tengut de pèrdua, que el feta haia, per ço com el tendra aquel comú malgrat dels personers desús dits.

(Llibre de Consolat dels fets maritims, 1592, segle xvib, p. 55)

(15) E si el los leva malgrat dels mercaders el nes tengut tot axi com ia desús es dit [...]. (Llibre de Consolat dels fets marítims, 1592, segle xvib, p. 66)

La conceptualització de l'esquema de la [CONTRA VOLUNTAT] en un escenari espacial-temporal (Palmer, 1994) es materialitza, com veiem a l'exemple (16), amb l'ús del verb de moviment venir i el pronom feble de complement indirecte li en la construcció venir + «a Déu» + mal + possessiu + grat.

(16) PERE. Què vol dir açò? Aquesta alegria prenia-la ab son vol, o, con fos plen de tantes virtutz, venia-li mal son grat?

GREGORI. Pere, gran és la dispensació de Déu, e sovén s’esdevén que en aquels en qui dóna los majors dons, alscuns petitz no ls vol donar, per tal que tostemps troben en sí alcuna cosa de reprehension; per tal que, cant desigen ésser perfetz, e no ho poden ésser, e trebaylen en ayçò que no àn resebut, si ben s’í fan lur poder, que no ss donen vanaglòria d'açò que àn resebut, ans aprenen que d'éls matexes no àn los grans béns, pus que en sí matexes no poden vençre los pati[t]s vicis que en sí àn.

(Montserrat Alegre, 1340, segle xiva, Diàlegs de Sant Gregori, fol. 43v., 1. 1)

Les estructures contra + possessiu + grat $\mathrm{i}$ contra + grat ${ }^{4}$, datades del segle XV, corroboren la hipòtesi

4 Rofes (2012) estudia les construccions concessives al Curial e Güelfa.

SCRIPTA, Revista internacional de literatura i cultura medieval i moderna, núm. 12/ desembre 2018/pp. 86-102

ISSN: 2340 - 4841 doi:10.7203/SCRIPTA.12.13665 
que aplicàvem a malgrat: 'allò que ens produeix [DESGRAT] va o es desplaça [CONTRA VOLUNTAT] nostra', de manera descontrolada i sense possibilitat d'evasió.

(17) -Cavaller, molt parlau descortesamet, car yo no ferí vostre cavall per ma volentat, mas, en aquell cas que yo fuy junt ab vós per ferir, ell alçà lo cap en manera que yo, contra mon grat, ferí allà on no haguera volgut; e per ventura lo cavall fonch causa de vostra salut e portà la pena de l'ultratge que vós me demanats.

(Enyego d’Àvalos 5 , 1442, segle xva, Curial e Güelfa, p. 145, 1. 40)

(18) E vull-te pregar e t prech que tu axí mateix prechs ton fill que, ab la sua treta d'or fira la senyora de Milà en la pus pregona part del seu cor, e la encena axí fort que no tròpia loch on pusca haver repòs; desig aquest cavaller e cerch via contra tot son grat com lo pusca haver, e un dia li sie un any a esperar-lo pregue aquells qui la solien pregar per ell, e ells anvides la vullen oyr; alarguen-li lo temps, usen envers ella segons que contra l'altre ella ha usat, e conega que los vots ne les promissions que ella ha fets en ofensa de la tua juredicció divinal, sens permissió tua, no ss poden servar sinó tant com a tu plau.

(Enyego d'Àvalos, 1442, segle xva, Curial e Güelfa, p. 145, 1. 40)

(19) E jatsia Curial per dues letres se fos escusat d' aquella batalla, obrint ab bona veritat tot lo cas que s'era seguit entre ell e Bertran del Chastell, lo dit Guillalmes, qui era molt ardit e forts, e molt ultrajós, e ab gran ergull en estrem, li replicà en tal manera e sots tal composició de paraules, que a Curial, segons art de cavalleria, fóra mills ésser mort en lo cativeri que escusar-se més avant d' aquella batalla. Per què hach, contra tot son grat, a acceptar-la e, puys que hach coneguda la volentat del cavaller, seguí-la axí en lo devisar de les armes com en la elecció e nominació de judge [...]

(Enyego d'Àvalos, 1442, segle xva, Curial e Güelfa, p. 353, 1. 3)

(20) Delits passats de la que àm m'acorden

contra mon grat, e les dolors m'obliden

$¿$ ¿ui són aquells que dins lo meu cor criden

e par a mi que són vèrmens qui m morden?

(Ausiàs Marc, segle xvb, Poema CXV, Poesies, 1. 62)

(21) Deus sap tot so que es passat, /Present e sdevenidor, / Doncs ell sabia sta amor /De lonc temps anans queu[s] nasqués; /E si no volgés queus amés, /No agra feyt, contra son grat /Obrera; e doncs es pausat /Que vol queus am, per que plaser /Vos deu [...] (Anònim, segle xvb, «Destret d'emors mi clam a vos», Salut d'amour, vv. 158-166)

(22) No puixa lo fill per tu scusar de complir ço que ha amprès, car res al món tant no 1 retrauria de la redempció a ffer, que ha conclusa e del liberada, com faria la displicència e contradicció tua, si sabia tu hi venguesses contra grat e forçada.

(Felip de Malla, 1495, segle xvb, Memorial del pecador remut, p. 240, 1. 20)

5 D’acord amb les primeres investigacions de Soler (2017) sobre l'autoria del Curial e Güelfa.

SCRIPTA, Revista internacional de literatura i cultura medieval i moderna, núm. 12/ desembre 2018/pp. 86-102 ISSN: 2340 - 4841 doi:10.7203/SCRIPTA.12.13665 


\section{Caterina Martínez. De l'[EMOció] a la [CONTRA voluntat]: el procés de gramaticalització de malgrat als segles XII-XVI}

En (23) i (24), la preposició $a$, amb una funció semblant al datiu de direcció (Yngles, 2011), apareix a la fi o al bell mig de la construcció amb malgrat, fent referència al Subjecte Agent [+animat] -'el demanador' i 'l'home-, i, semblantment, combinada amb pronoms possessius relatius al Subjecte Pacient [+animat] que experimenta la [CONTRA vOLUNTAT] -'els ciutadans' i 'tu mateix'.

(23) Con sia desús dit que si cases d'alcun veyn minantur ruinam, so és que si les dites cases volen caure e que sien en rech de caure, e que sia ver e clar enaxí que a les cases de son veyn, si aqueles cases cayen, pógen-se dan donar e a les coses que són layns, és electió d'aquel spera aquest don a pendre e aver que li deman fermansa, que si per caure d'aqueles cases él ne vènia dan, que lo y emenàs tot $\mathrm{e}$, si dar no la y volia, que anàs al veger e que se $n$ clam. E per sentencia dels ciutadans coven que 1 demanat dón fermansa, mal son grat al demanador, que si dón vènia al demanador que lo y refassa, o que derroch la paret o coberta a lò que vol caure e don pot donar; e assò és electió del demanador, qual que n vula demanar: o la fermansa, o el derrocar, o l'adobar si adobar se pot e lo demanat ha de què u pusca adobar.

(1272-1279, segle ximb, Costums de Tortosa, p. 166, 1. 4)

(24) Plató diu: «No desiges jamés de donar consell a l’home que haje senyoria o libertat sobre tu, perquè si per fortuna li tornàs en dany, ell t'ó faria portar e comprar mal a ton gratı.

(1495, segle xvb, Flors de virtut, p. 126, 1. 4)

Sorprenentment, fins al segle xIvb, no hem atestat la variant a malgrat de, encapçalada per la preposició $a$, anàloga de la construcció a pesar de-documentada ja en català al segle XII en el Llibre dels fets de Jaume I (DECat, s. v. pesar).

Així, doncs, coetània de en desgrat de -atestada segle xiva en els Clams i crims a la València medieval-i de a despit de -al segle xivb en la Crònica de Ramon Muntaner (DECat, s. v. despit)-, a malgrat de indica que el Subjecte Pacient [+animat], introduit per de i/o per un possessiu, experimenta un sentiment de [CONTRA VOLUNTAT] produit pel que s'expressa prèviament en la pròtasi condensat en la preposició dativa de direcció $a$. Concretament, les locucions de a malgrat de són: $a+$ mal + possessiu + grat $-\mathrm{vg}$. (25) «(de) les dones»-; $a+$ mal + grat + de - vg. $(26) \ll(\mathrm{d})$ els sicilians» $\mathrm{i}(29) \ll(\mathrm{de})$ mols»-; $a+$ possessiu + mal + grat - vg. $(27) \ll(d ')$ ella y (d)els seus»-; i $a+$ mal + grat + possessiu - vg. $(28) \ll(\mathrm{de})$ Tirant»-:

(25) O quantes infanten abans de lur temps, tements que no venguen a vergonya! Si l'arbre qui lurs malvestats cobre sabia parlar, ell diria qui l'ha despullat. Quants te penses que sien los parts qui a mal lurgrat són venguts a bé, e elles los giten a la fortuna? Los hospitals ho saben e los boscatges e los rius e los pous, hon molts infants són gitats; e los peys, ocells e bèsties feres que devorats los han. (Bernat Metge, 1399, segle xivb, Lo Somni, p. 204, 1. 21)

(26) E una nit lo dit baró ab las gents partiren e feren lo camí de Castro Johan, qui solament lo castell se tenia per lo rey, e fins a Cathània tota l'altra terra era rebella, però lo noble baró travessà la més part de la Illa e del Regne ab tota la sua companya amalgrat dels sicilians, e anà soccórrer lo rey e lo infant, son pare, lo qual trobà en lo castell de Cathània que la ciutat fora rebellada contra ells, e tantost com lo dit noble baró fon junt en lo Castell de Cathània e durà lo dit siti vi mesos [...](Pere Tomic, 1438, segle xva, Histories e conquestes dels Reys de Aragó e Comtes de Barcelona, fol. LXIv; DCVB, s. v. grat) 
(27) Sols prosperàs / ella y els seus, / fent-los ereus / de sos regnats. / Per tals peccats, / fon ben rodada / he turmentada. / Moltes cremades / de ses criades, / a llur mal grat.

(Jaume Roig, 1460, segle xvb, Spill, 1. 1381)

(28) Cridà la princessa e a Tirant, e mostrà ls la camisa e dix:

- Aquesta sanch mia ha força de reparar amor.

E tot açò deÿa ab les làgremes als ulls. Aprés dix:

- Qui haurà grat de mi, ni qui fiarà de mi, que no hé sabuda guardar a mi matexa? Com serà per mi guardada altra donzella que acomanada $\mathrm{m}$ sia? No tinch conort sinó de una cosa: que no hé res fet que perjudique la honor de mon marit, sinó que hé complida sa voluntat a mal grat meu. En les mies bodes no y són venguts los cortesans, ni capellà no s’és vestit a dir la missa. No y és venguda ma mare ni mes parentes. No han agut treball de despullar-me les robes e vestir-me la camisa nubcial. No ha 'm pujada al lit per força, car yo m’í só sabuda pujar. No han agut treball los ministrés de sonar ni de cantar, ni los cortesans cavallers de dançar, que bodes sordes són stades. Emperò tot lo que hé fet resta en grat de mon marit.

(Joanot Martorell, 1490, segle xvb, Tirant lo Blanch, p. 709, 1. 1)

(29) Lo capità dels cristians fou monsenyor Pere Farran, mercader, lo qual anava vestit tot blanc ab una calsa de talilla de plata ab una guera de Córdova ab pasamans de plata ý fullateria; lo seu alferis fou monsenyor Jofre, argenter, ý molt a mal grat de mols, lo qual aportava una calsa de vellut negra ab enforros de brocat, lo sargento fou monsenyor Solís, mercader, lo qual anava vestit tot de satí negra.

(Jeroni de Saconomia, 1572-1601, segle xvib, Memòries de Jeroni de Saconomia, p. 198, 1. 24)

I, fins ací, arriba el camí de gramaticalització de malgrat. Dissortadament, a partir del segle XVI, no hem aconseguit atestar cap altre exemple de malgrat que constate el sorgiment de cap altre valor, semblant al que avui ha assumit. En textos de caràcter popular, excepcionalment, com ara entremesos o sainets del segle XVII i XVIII, tornem a trobar malgrat amb valor de [CONTRA VOLUNTAT] combinat amb possessius i amb de vinculats, encara, a un Subjecte [+animat] -vg. (30), (31) i (32)-.

(30) MORLÀ: Sastre.

MALUENDA: Si és sastre, podrà,

per a que agarren les dones

en lo joc del demanar,

molt profitós per a elles,

donar ungles a les mans.

Apee's de l'eco, i diga

qui és; si no, li faran

los jutges i el secretari

que ho diga, mal de son grat.

(Pere Jacint Morlà, 1627, segle xvıIa, Poesies i col loquis, p. 263)

(31) Entra en Rossell /ab traïció i manya, / cridant i dient: / «Vixca el rei de Espanya!» / - a mal de son grat /dient tal paraula, /que és cert /de plaer ni gana; /sí per enganyar /a la gent païsana.

(Pere Esteve, 1658, segle xvirb, Escrits valencians, pp. 79-80) 
Caterina Martínez. De l'[EMOció] a la [CONTRA voluntat]: el procés de gramaticalització de malgrat als segles XII-XVI

(32) Ho féu així el venerable apostòlich y en esta segon visita li intimà la magestat que no se'n tornara a València sens la sua expressa real llicència; ants sí, continuar en visitar-lo. Convingué el venerable a mal de son grat y aquells dies eixercitava el ministeri de la predicació per vicos et plateas quarens; per places y carrers, buscant les ovelles perdudes y les ànimes per al Senyor. (Leopold Ignasi Planells, 1760, segle xvirb, Vida del Pare Esteve, p. 95)

Així mateix, nosaltres trobem paral lelismes clars entre el procés de gramaticalització de malgrat i el de la construcció a pesar de -excel lentment explicada per Pérez Saldanya (2014) en espanyol-. Aquests paral lelismes i una justificació plausible seran objecte d'estudi de treballs a venir.

\section{Conclusions}

La primera i la segona fase de la gènesi del connector parentètic malgrat presenten singularitats que són molt destacables i que no havien estat mostrades fins ara. D’aquesta anàlisi deduïm les conclusions següents:

a) Malgrat, mot de procedència popular, és producte d'un canvi semàntic propi de paraules més aviat cultes. Ben enjorn, des dels segles XII-XIII, aquest Sintagma Nominal que denotava una [emoció desagradable] esdevingué un Sintagma Preposicional amb valor de [Contra voluntat] experimentada per un Subjecte [+animat]. I, a partir del segle XVI, desaparegué sense deixar rastre.

b) Els connectors parentètics de contrast concessiu que brollen de la font conceptual de l'[EXPERIÈNCIA EMOCIONAL], com ara a pesar de (Garachana, 1997; Garrido, 2006; Herrero, 2012; Pérez Saldanya, 2014), baldament (Martínez, en premsa) o, com hem vist ací, malgrat, estan lligats a les reaccions dels interlocutors davant de cadascuna de les situacions comunicatives concretes, que dispararan en el canvi lexicosemàntic. Aquests connectors modalitzats - pel $\mathrm{Pt} / \mathrm{Er}-\mathrm{i}$, conseqüentment, intersubjectivats - pel Pt/Er, atenent el(s) Ot(s)/Lr(s)-, que serveixen per a comunicar i negociar amb experiències sensitives, emocionals, racionals i/o morals, individuals i compartides (Nuyts, 2005; Traugott, 2010; Narrog, 2012), han acabat gramaticalitzant-se en connectors parentètics de contrast [CONCESSIU].

c) La recursivitat que s'observa en l'evolució des d'un significat d'[EXPERIÈNCIA EMOCIONAL], concretament de [DESGRAT], a un de [CONTRA VOLUNTAT] als segles XII-XVI, fins al contemporani de [CONCESSIVITAT], és una manifestació més de la regularitat del canvi semàntic (Traugott, 1989; Traugott \& Dasher, 2002). Aquesta afinitat entre els diferents dominis conceptuals manifestada, sincrònicament, per una gran varietat de llengües (König, 1985; 1988), corrobora la hipòtesi de la Lingüística Cognitiva: l'existència d'una xarxa de nodes semàntics compartits, d'una arrel cognitiva comuna, darrere de cada peça lingüística, en constant evolució. 
Caterina Martínez. De l'[EMOció] a la [CONTRA voluntat]: el procés de gramaticalització de malgrat als segles XII-XVI

d) Sembla que, entre els segles XVI-XVIII, el procés de gramaticalització de malgrat es va truncar, ja que no hem atestat cap altre exemple de malgrat que mostre el sorgiment de cap altre valor, semblant al que avui ha assumit. Tal com hem promès de fer, les possibles explicacions d'aquesta sobtada caiguda en desuetud de malgrat són el títol de la continuació d'aquest estudi: la tercera i la quarta fase de malgrat.

\section{Bibliografia}

Badia i Margarit, A. (1994) Gramàtica de la llengua catalana: descriptiva, normativa, diatòpica, diastràtica, Barcelona, Proa.

CICA = Torruella, J. (dir.) \& Martines, J. \& Pérez Saldanya, M. (2008) Corpus Informatitrat del Català Antic.

SCRIPTA, Revista internacional de literatura i cultura medieval i moderna, núm. 12/ desembre 2018/pp. 86-102 ISSN: 2340 - 4841 doi:10.7203/SCRIPTA.12.13665 
Caterina Martínez. De l'[EMOció] a la [CONTRA voluntat]: el procés de gramaticalització de malgrat als segles XII-XVI

CIMTAC = Martines, J. \& Martines, V. (dirs.) Corpus Informatitzat Multilingüe de Textos Antics $i$ Contemporanis, Alacant, ISIC-IVITRA.

Consales, I. (2005) La concessività nella lingua italiana (secoli XIV-XVIII), Studi linguistici e di storia della lingua italiana, Collana diretta da Maurizio Dardano, 6.

Cuenca, Mª J. (1990) «Els matisadors: connectors oracionals i textuals», Caplletra, 8, pp. 149-167.

Cuenca, $\mathrm{M}^{\mathrm{a}} \mathrm{J}$. (2001) «Los conectores parentéticos como categoría gramatical», Lingüistica Española Actual, XXIII, 2, pp. 211-235.

Cuenca, $\mathrm{M}^{\mathrm{a}} \mathrm{J}$. (2006) La connexió $i$ els connectors. Perspectiva oracional $i$ textual, Vic, Universitat de Vic, Eumo Editorial.

DAguiló = Aguiló, M. (1924) Diccionari Aguiló, Institut d'Estudis Catalans.

DCVB = Alcover, A. \& de Borja Moll, F. (1985) Diccionari Català-Valencià-Balear, Palma, Moll.

DECat = Coromines, J. (1995) Diccionari Etimologic i Complementari de la llengua catalana, Barcelona, Curial \& La Caixa.

DEscrig = Escrig, J. (1891) Diccionario valenciano-castellano, València, Libreria de Pascual Editor (http:// www.cervantesvirtual.com/obra/diccionario-valencianocastellano-volumen-i-aestalviu--0/)

DLabèrnia = Labèrnia, P. (1865) Diccionari de la llengua catalana ab la correspondencia castellana y llatina, Barcelona, Espasa Germans.

DMistral = Mistral, F. (1878) Dictionnire provençal-français embrassant les divers dialectes de la langue d'oc moderne, Culture provençale et méridionale, Raphèle-lès-Arles (https:/ gallica.bnf.fr/ark:/12148/ bpt6k74854/f1.image)

Ferrando, A. (ed.) (2004) Moments clau de la història de la llengua catalana d'Antoni Badia i Margarit, València, Universitat de València, Col. Honoris Causa.

Garachana, M. (1997) Los procesos de gramaticalización. Una aplicación a los connectores contraargumentativos, Tesi doctoral, Barcelona, Universitat de Barcelona.

Garachana, M. (2013) «Ço és (a saber): la reformulació als textos catalans antics», dins Casanova, E. \& Calvo, C. (eds.) Actas del XXVI Congreso Internacional de Lingüistica y de Filología Románicas, 7 , Berlín, De Gruyter, pp. 151-162.

Garrido, $M^{\mathrm{a}}$ (2006) «Gramaticalización y marcadores del discurso: los contraargumentativos», Estudios humanísticos. Filología, 28, p 9-26.

GCC = Solà, J. (dir.), Lloret, M. R., Mascaró, J. \& Pérez Saldanya, M. (eds.) (2002) Gramàtica del Català Contemporani, vol. 3, Barcelona, Empúries.

GIEC = Institut d'Estudis Catalans (2017) Gramätica de l'Institut d'Estudis Catalans, Barcelona.

Harris, M. (1988) «Concessive clauses in English and Romance», dins Haiman, J. \& Thompson, S. (eds.) Clause Combining in Grammar and Discourse, Amsterdam/Philadelphia, John Benjamins, pp.

SCRIPTA, Revista internacional de literatura i cultura medieval i moderna, núm. 12/ desembre 2018/pp. 86-102 ISSN: 2340 - 4841 doi:10.7203/SCRIPTA.12.13665 
Caterina Martínez. De l'[EMOció] a la [CONTRA voluntat]: el procés de gramaticalització de malgrat als segles XII-XVI

$71-99$

Heine, B. (1997) Cognitive Foundations of Grammar, New York/Oxford, Oxford University Press.

Herrero, F. J. (2012) «Conectores contraargumentativos en espanyol. Semejanzas y diferencias en su origen y desarrollo», Actas del II Coloquio Marcadores del discurso en lenguas románicas: un enfoque contrastivo, pp. 113-123.

Ibba, D. (2008) Los procesos de gramaticalización de algunos conectores concesivos del castellano medieval, Tesis doctoral, Barcelona, Universitat Autònoma de Barcelona.

König, E. (1985) «Where do concessives come from? On the development of concessive connectives», dins Fisiak, J. (ed.) Historical semàntics: Historical word formation, Berlin, Mouton de Gruyter, pp. 263-282.

König, E. (1988) «Concessive connectives and concessive sentences: cross-linguistic regularities and pragmatic principles», dins Hawkins, J. (ed.) Explaining language universals, vol. vI, London, Blackwell, pp. 145-166.

Lakoff, G. (1987) Women, Fire and Dangerous Things: What Categories Reveal about the Mind, Chicago, Chicago University Press.

Martínez, C. (2018) La gramaticalitració dels connectors de contrast: estudi de corpus $i$ aproximació segons la Teoria de la Inferència Invitada del Canvi Semàntic, Tesi doctoral, Alacant, Universitat d'Alacant.

Martínez, C. (en premsa) «Baldament en el Curial e Güelfa: a les portes del valor concessiu».

Montero, E. (1992) «La trayectoria cronològica y modal de la expresión concessiva maguer(a) (que)», dins Ariza, M., Cano, R., Mendoza, J. M., \& Narbona, A. (eds.) Actas del II Congreso Internacional de Historia de la Lengua Española, 1, Madrid, Asociación de Historia de la Lengua Española, pp. 701-710.

Narrog, H. (2012) Modality, subjectivity and semantic change: a cross-linguistic perspective, Oxford, Oxford University Press.

Nuyts, J. (2005) «Modality: overview and linguistic issues», dins Frawley, W. (ed.) The expression of modality, Berlin/New York, Mouton de Gruyter, pp. 1-26.

Palmer, F. (1994) Grammatical Roles and Relations, Cambridge, Cambridge University Press.

Pérez Saldanya, M. \& Salvador, V. (1995) «Fraseologia de l'encara i processos de gramaticalització», Caplletra, 18, pp. 85-108.

Pérez Saldanya, M. (2014) «Oraciones concesivas», dins Company, C. (dir.) Sintaxis Histórica de les Lengua Española. Tercera parte: Adverbios, preposiciones y conjunciones. Relaciones insteroracionales, México, Universidad Nacional Autónoma de México, Fondo de Cultura Económica, pp. 3699-3839.

Rofes, X. (2012) «Les construccions concessives en el Curial e Güelfa», dins Ferrando, A. (ed.) Estudis lingüistics i culturals sobre Curial e Güelfa. Novel la cavalleresca, Amsterdam/Philadelphia, John Benjamins Publishing Company, pp. 743-794. 
Caterina Martínez. De l'[EMOció] a la [CONTRA voluntat]: el procés de gramaticalització de malgrat als segles XII-XVI

Rofes, X. (2017) «Les oracions concessives», Conferència pronunciada el 4 de febrer de 2017 en el VIII Simposi Internacional Vers una Sintaxi Històrica del Català, X Simposi Internacional Noves Tendències en I+D+I en Literatura, Llengua, Educació i TIC sobre la Corona d'Aragó. De la innovació al cànon, Alacant/La Nucia, Universitat d'Alacant.

Rossari, C. (2014) «How does a concessive value emerge?», dins Ghezzi, C.a \& Molinelli, P. (eds.) Discourse and Pragmatic Markers from Latin to the Romance Languages. Oxford Studies in Diachronic and Historical Linguistics, Oxford, Oxford University Press, pp. 237-259.

Rudolph, E. (1996) Contrast: Adversative and Concessive Expressions on Sentence and Text Level, Berlin, Mouton de Gruyter.

Salvador, V. (2010) «Entre la retòrica i la gramàtica: estructures de la concessivitat en català», dins Faluba, K. \& Sziji, I. (eds.) Actes del XIVè Col toqui Internacional de Llengua i Literatura Catalanes, Barcelona, Publicacions de l'Abadia de Montserrat, pp. 17-42.

Soler, A. (2017) La cort napolitana d'Alfons el Magnànim: el context del Curial e Güelfa, 3 vols., València, Institució Alfons el Magnànim, Institut d'Estudis Catalans.

TLFi $=$ Trésor de la Langue Française informatisé (http://atilf.atilf.fr/tlf.htm).

Traugott, E. (1989) «On the rise of epistemic meanings in English: An exemple of subjectification in semantic change», Language, 65, pp. 31-55.

Traugott, E. (1990) «From less to more situated in language: the unidirectionality of semantic change», dins Adamson, S. et al. (eds.) Papers from the Fifth International Conference on English Historical Linguistics, Amsterdam, John Benjamins, pp. 496-517.

Traugott, E. \& Dasher, R. (2002) Regularity in Semantic Change, Cambridge, Cambridge University Press.

Traugott, E. (2010) «Revisiting Subjectification and Intersubjectification», dins Davidse, Kristin et al. (eds.) Subjectification, Intersubjectification and Grammaticalization, Berlin, Mouton de Gruyter, pp. 29-70.

Yngles, M. T. (2011) El datiu en català: una aproximació des de la lingïística cognitiva, Barcelona, Publicacions de l'Abadia de Montserrat. 